\title{
Free Radical-Induced Site-Specific Peptide Cleavage in the Gas Phase: Low-Energy Collision-Induced Dissociation in ESI- and MALDI Mass Spectrometry
}

\author{
Huiyong Yin, Almary Chacon, and Ned A. Porter \\ Department of Chemistry, Center in Molecular Toxicology, Vanderbilt Institute of Chemical Biology, \\ Vanderbilt University, Nashville, TN 37235, USA \\ Huiyong Yin \\ Division of Clinical Pharmacology, Vanderbilt University, Nashville, TN 37235, USA
}

\author{
Douglas S. Masterson* \\ Department of Chemistry and Biochemistry, The University of Southern Mississippi, Hattiesburg, \\ MS 39406, USA
}

Protein identification is routinely accomplished by peptide sequencing using mass spectrometry (MS) after enzymatic digestion. Site-specific chemical modification may improve peptide ionization efficiency or sequence coverage in mass spectrometry. We report herein that amino group of lysine residue in peptides can be selectively modified by reaction with a peroxycarbonate and the resulting lysine peroxycarbamates undergo homolytic fragmentation under conditions of low-energy collision-induced dissociation (CID) in electrospray ionization (ESI) and matrix-assisted laser desorption and ionization (MALDI) MS. Selective modification of lysine residue in peptides by our strategy can induce specific peptide cleavage at or near the lysine site. Studies using deuterated analogues of modified lysine indicate that fragmentation of the modified peptides involves apparent free-radical processes that lead to peptide chain fragmentation and side-chain loss. The formation of a-, c-, or z-types of ions in MS is reminiscent of the proposed free-radical mechanisms in low-energy electron capture dissociation (ECD) processes that may have better sequence coverage than that of the conventional CID method. This site-specific cleavage of peptides by free radical- promoted processes is feasible and such strategies may aid the protein sequencing analysis and have potential applications in top-down proteomics. (J Am Soc Mass Spectrom 2007, 18, 807-816) (c) 2007 American Society for Mass Spectrometry

$\mathrm{M}$ ass spectrometry (MS) plays an indispensable role in identification of proteins in complex mixtures by providing sequences for peptides after enzymatic digestions [1, 2]. The sequencing is often accomplished using tandem mass spectrometry (MS/MS) by collision-induced dissociation (CID) or electron capture dissociation (ECD) of protonated species $[3,4]$. Chemical modification of peptides or proteins has also provided strategies that are helpful in

Published online February 16, 2007

Address reprint requests to Dr. Huiyong Yin, Departments of Medicine and Chemistry, Division of Clinical Pharmacology, Vanderbilt University, RRB 526B, Nashville, TN 37232-6002. E-mail: huiyong.yin@ vanderbilt.edu

* Department of Chemistry and Biochemistry, The University of Southern Mississippi, Hattiesburg, MS 39406, USA. E-mail: Douglas.Masterson@ usm.edu assignment of peptide sequence, enhancement of the MS sensitivity [5], and, importantly, in protein quantification [6]. Even though database searches for protein identification are primarily based on $b$ - and $y$-ions observed in MS/MS spectra, complex fragmentation patterns can result from the ECD process and improve the sequence coverage in protein identification $[7,8]$. The typical a-, c-, and z-fragments in ECD are postulated to arise from free-radical intermediates. The nomenclature of the fragments as proposed by Roestorff is shown in Scheme 1 [9].

In a recent communication we reported a method to generate radicals in a site-specific manner on peptides in the gas phase, after modification of lysine residues as peroxycarbamates [10]. Fragmentation appears to result from initial free-radical dissociation of the peroxide bond followed by decarboxylation. The chemistry can 


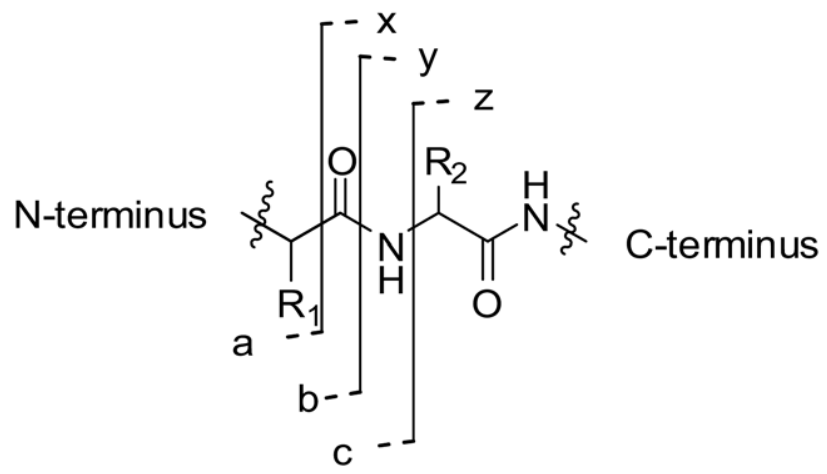

Scheme 1

also be used for N-terminus amino acid identification based on the neutral loss of the side chain [11]. The "digestion" of peptides or proteins in the gas phase after chemical derivatization may provide an alternative to enzyme digestion and could potentially increase the throughput of proteomics analysis. Here we report a detailed study of the free-radical mechanisms and fragmentation pathways generated in the gas phase of MS after lysine modification by peroxycarbamate chemistry. The free radical-induced peptide fragmentation results from the selective modification of lysine residues, which may help to assign the peptide/protein sequences in a top-down approach of proteomics [12].

\section{Experimental}

$\mathrm{N}$-Acetyl lysine was purchased from Aldrich Chemical Co. (Milwaukee, WI, USA) as methyl ester derivatives in their hydrochloride salt forms. Peptides were purchased from American Peptide Company (Sunnyvale, CA, USA). Solvents were HPLC grade, obtained from Fisher Scientific (Pittsburgh, PA, USA). All other reagents were purchased from Aldrich Chemical. $t$-Butyl $p$-nitrophenyl peroxycarbonate and its deuterated analogues were synthesized according to a previously published procedure [10]. Acetate buffers $(10 \mathrm{mM})$ of various $\mathrm{pH}$ values were prepared from ammonium acetate titrated to $\mathrm{pH} 5.2,5.5$, and 5.8 with acetic acid. Tris buffers were $0.1 \mathrm{M}$ solutions titrated to $\mathrm{pH} 7.5$ and $\mathrm{pH} 8$, respectively. Ammonium bicarbonate buffer was a $0.1 \mathrm{M}$ solution at $\mathrm{pH}$ 8.6. Buffer systems used to modify peptides and amino acids consisted of a 1:1 mixture of the appropriate buffer and acetonitrile.

MS analyses of modified single amino acid derivatives and peptides were performed on a Thermo Electron Corporation (San Jose, CA, USA) TSQ 7000 or ThermoFinnigan TSQ Quantum 1.0 SR 1 mass spectrometer triple-quadrupole instrument, equipped with an electrospray ionization (ESI) source. The capillary temperature was kept at $200{ }^{\circ} \mathrm{C}$. The electrospray needle voltage was $4.5 \mathrm{kV}$, and the tube-lens voltage was maintained between 70 and $100 \mathrm{~V}$. The sheath and auxiliary gases $\left(\mathrm{N}_{2}\right)$ were adjusted to maximize the signal.
Samples were introduced into the ESI source as either lithium chloride solutions or acidic solutions at a rate of 10 to $20 \mu \mathrm{L} / \mathrm{min}$ in direct liquid infusion experiments. For LC-MS analyses of peptides, a Grace Vydac (Hesperia, CA, USA) C18 column $(10 \mathrm{~cm} \times 1 \mathrm{~mm})$ was used. The solvent conditions consisted of a 20-min gradient from 5 to $50 \%$ solvent B ( $95 \%$ acetonitrile, $5 \%$ water, $0.05 \%$ TFA) into solvent A ( $95 \%$ water, $5 \%$ acetonitrile, $0.05 \%$ TFA). MALDI spectra were obtained on an Applied Biosystems 4700 Proteomics Analyzer using $\alpha$-cyano-4hydroxycinnamic acid as the matrix. The MS fragments are assigned based on the calculation of a web-based software MS-Products from UCSF (http://prospector. ucsf.edu/ucsfhtml4.0/msprod.htm).

\section{Results}

The selective modification of lysine or $\mathrm{N}$-terminus of a peptide is based on the peroxycarbamate chemistry reported recently [10,11]. Modification can be achieved by reaction of the peptide solution in ammonium bicarbonate buffer with $t$-butyl $p$-nitrophenyl peroxycarbonate. The appearance of an immediate yellow color indicates the formation of $p$-nitrophenoxide. Even though $\mathrm{N}$ terminus and lysine residues can be modified using the reagent, experimental conditions, especially the $\mathrm{pH}$ of the reaction medium, can be optimized to primarily

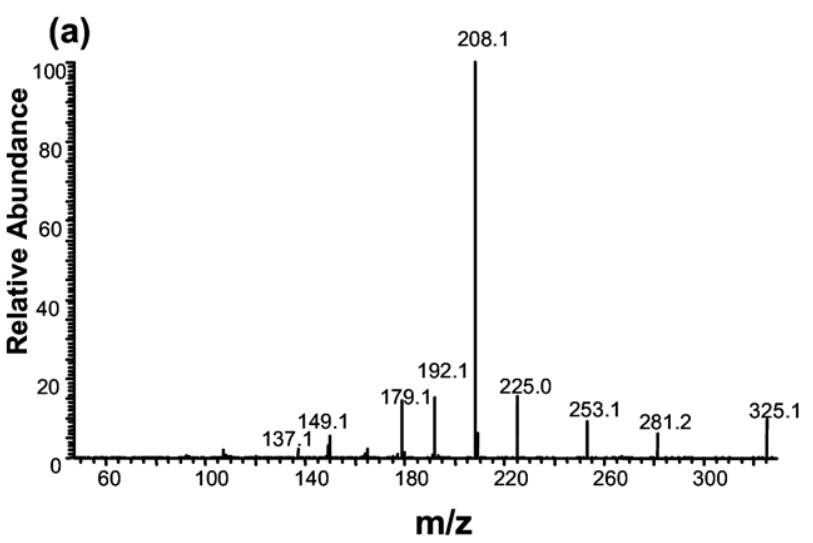

(b)

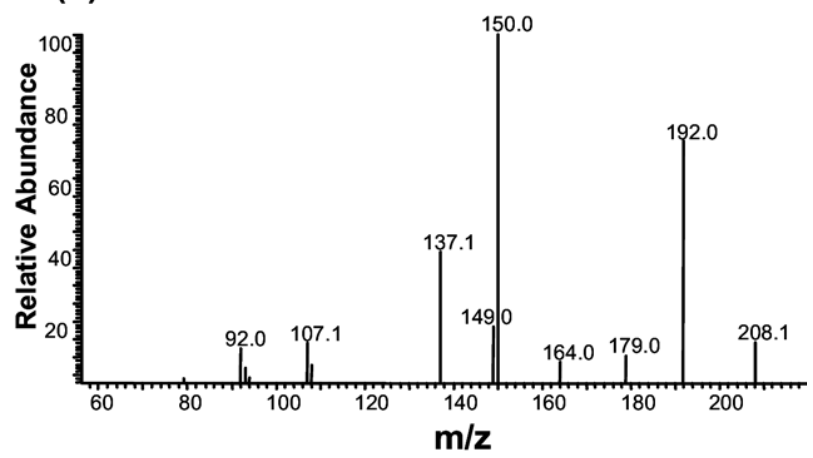

Figure 1. (a) CID spectrum of lithium adduct of peroxycarbonatemodified $\mathrm{N}$-acetyl lysine methyl ester ( $\mathrm{m} / \mathrm{z} 325)$; (b) CID of putative aminyl radical $m / z 208$. 

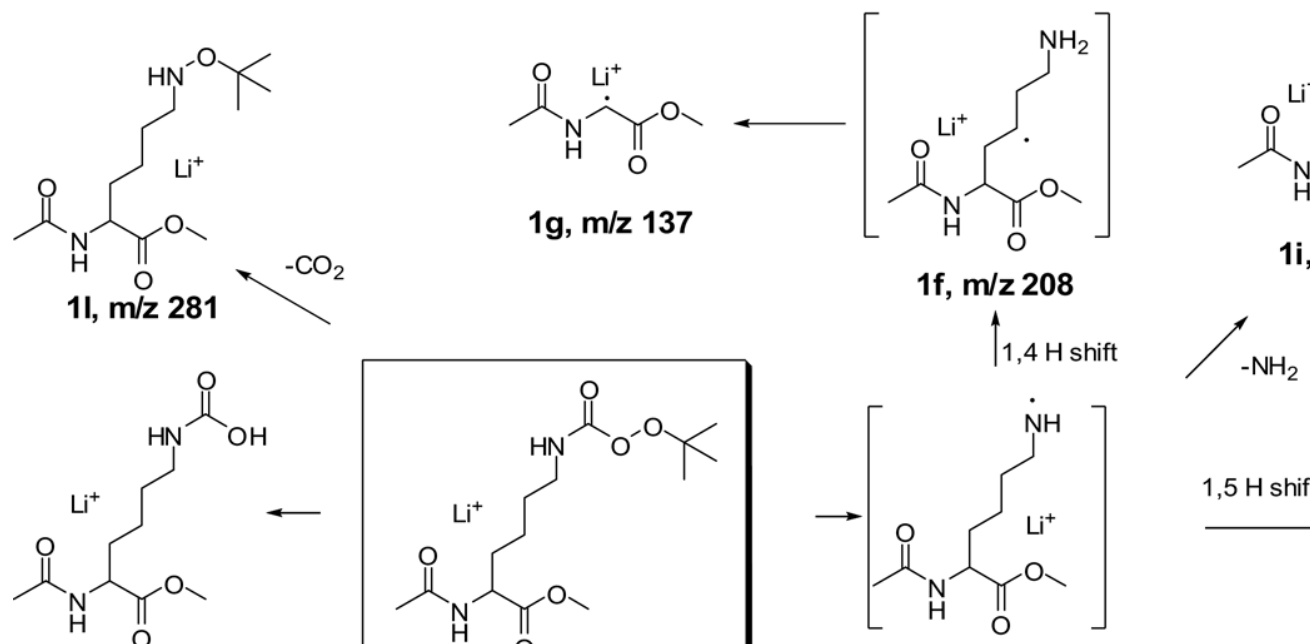<smiles>C=CCCC(NC(C)=[OH+])C(=O)OC</smiles>

1i, m/z 192<smiles>C=CC(NC(C)=[OH+])C(=O)OC</smiles>

1e, m/z 164<smiles>COC(=O)C(CCCCNC(=O)O)NC(C)=O</smiles>

1m, m/z 253<smiles>COC(=O)C(CCCNO)NC(C)=O</smiles>

1n, m/z 225

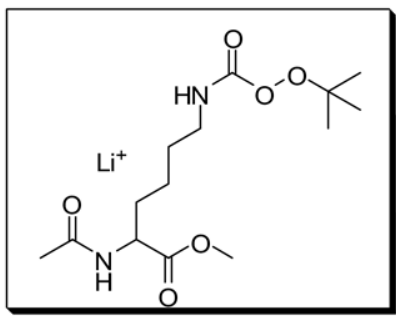

1a, m/z 325

1b, m/z 208<smiles>COC(=O)C(C[Te])NC(C)=O</smiles><smiles>CCC(NC(C)=[OH+])C(=O)OC</smiles>

1j, m/z 179<smiles>COC(=O)C(=[TeH+])NC(C)=O</smiles>

$1 \mathrm{k}, \mathrm{m} / \mathrm{z} 150$<smiles>CCC(=O)NC(CCCCN)C(=O)OC</smiles>

1h, m/z 208 1c, m/z 208<smiles>CC(=O)N/C=C/CCCN</smiles>

Scheme 2

modify lysine because the $\mathrm{p} K_{a}$ for terminal $\alpha$-amino group is about 8 , whereas the $\varepsilon$-amino group of the lysine residue has a $\mathrm{p} K_{a}$ of 10.7 [11].

\section{CID Experiments on a Modified Model Lysine}

$\alpha$-N-Acetyl lysine methyl ester was used as a model compound to test the modification as well as the gas-phase CID fragmentation pattern in ESI-MS. The CID spectra of modified $\mathrm{N}$-acetyl lysine methyl ester $\mathrm{Li}$ adduct $\mathrm{m} / \mathrm{z} 325$ (parent ion) and $\mathrm{m} / \mathrm{z} 208$ (putative intermediate aminyl radical) are illustrated in Figure 1.
The ion $\mathrm{m} / \mathrm{z} 208$ was generated in ionization source by increased spray voltage (source CID). The proposed free-radical pathways that lead to the resulting fragments are summarized in Scheme 2.

Major fragments (from $\mathrm{m} / \mathrm{z} 325,1 \mathbf{1 a}$ ) appear to be formed from the common aminyl radical intermediate $\mathbf{1 b}(\mathrm{m} / \mathrm{z} 208)$ produced from the homolytic cleavage of the peroxyl bond followed by decarboxylation. Similar fragments are generated from $\mathrm{m} / \mathrm{z} 208$ as a parent ion when the spray voltage is increased (Figure 1b). The intermediacy of the ion with $\mathrm{m} / \mathrm{z} 208$ is supported by experiments showing fragment intensities formed from

Table 1. Major fragments in CID spectra of peroxylcarbamate $N$-acetyl lysine methyl esters and its deuterated analogues

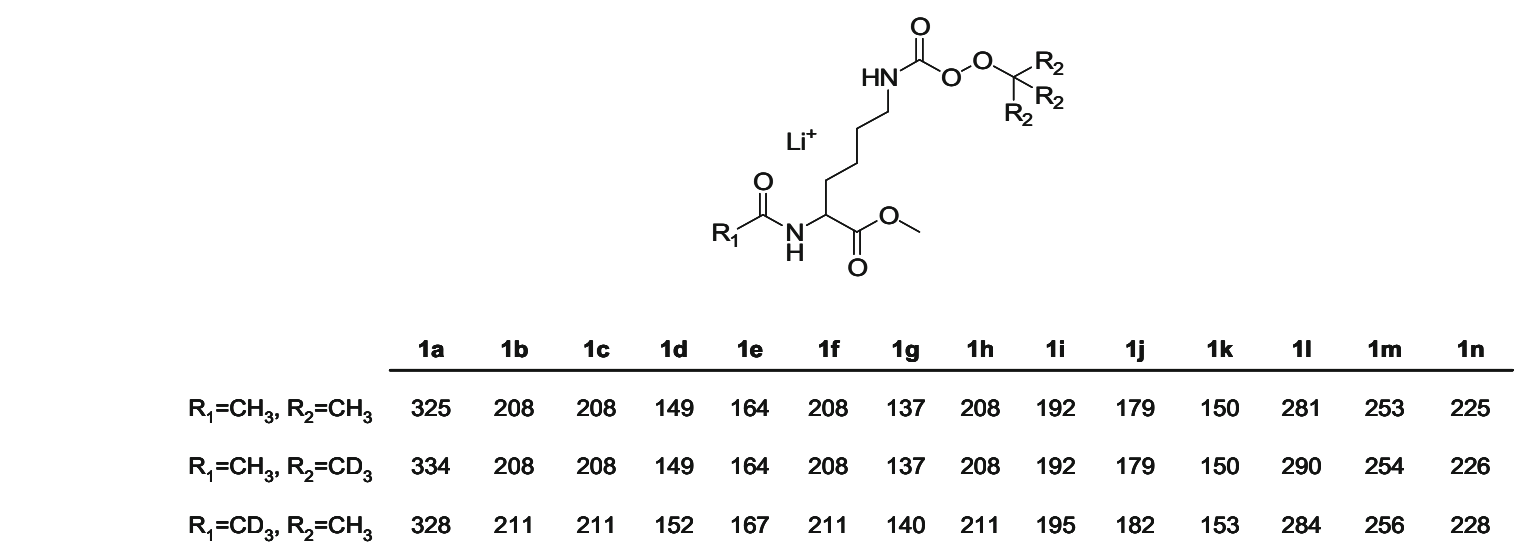


(a)

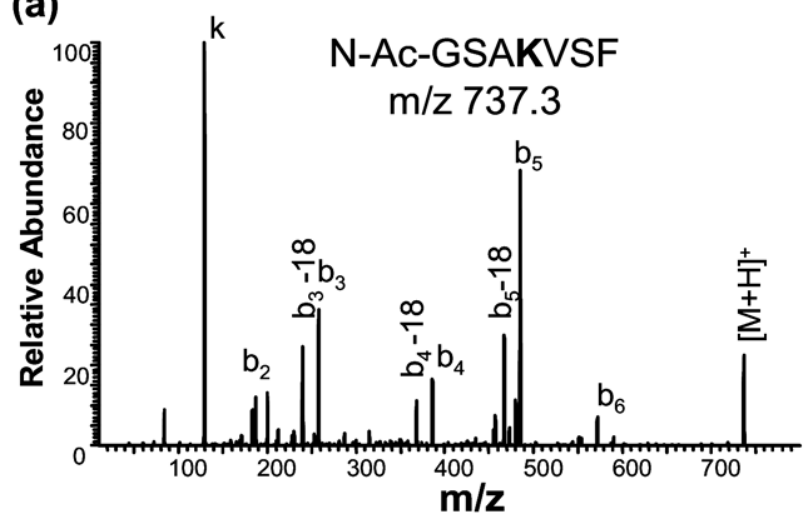

(b)
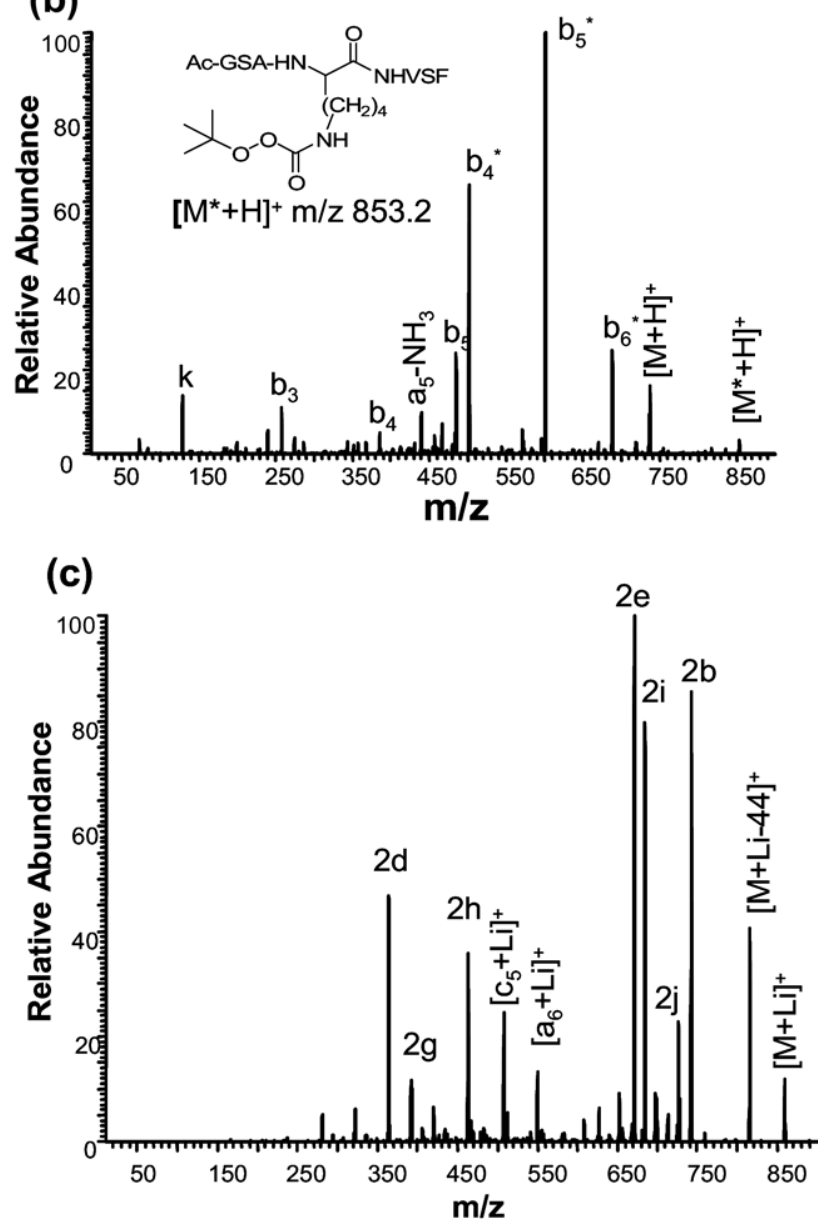

Figure 2. MS/MS spectra from CID of intact and modified 7-mer N-Ac-GSAKVSF. (a) Unmodified peptide $\mathrm{m} / \mathrm{z}$ 737.3; (b) modified peptide $\mathrm{m} / \mathrm{z} 853.2$ (protonated), *fragments with the $t$-butyl peroxycarbamate attached; (c) Li adduct of modified peptide $\mathrm{m} / \mathrm{z}$ 859.2 .

$\mathrm{m} / \mathrm{z} 325$ plotted against the CID offset energy [10]. With an increase of CID offset energy, the parent ion $\mathrm{m} / \mathrm{z} 325$ decreases, whereas the intensity of ion with $\mathrm{m} / \mathrm{z} 208$ is maximal at about $18 \mathrm{eV}$. This CID offset energy is much lower than the conditions required to obtain peptide backbone fragmentation (normally $>30 \mathrm{eV}$ using the same instrument), such as b- and y-ions for the sequencing purposes. The lower energy required is presumably because the energy required to cleave the peroxyl bond is much lower than that to break the peptide backbone $[13,14]$. Thus the major pathway of the lysine peroxycarbamate $\mathbf{1 a}$ is the generation of aminyl radical $\mathbf{1 b}(\mathrm{m} / \mathrm{z}$ 208) by homolytical cleavage of the peroxyl bond and decarboxylation.

Aminyl radical $\mathbf{1 b}$ can abstract hydrogen atoms from the side chain of lysine or from the peptide backbone. Fragments 1d (a-ion, $m / z 149)$ and 1 e $(m / z 164)$ can be generated from the $\beta$-fragmentation of radical $1 \mathbf{c}$, which is produced from a 1,5 hydrogen shift (Hoffman- LoefflerFreytag reaction) by a six-membered ring transition state [15]. The formation of this a-ion from the modified lysine could potentially be used for peptide sequencing purposes. Similarly, fragment $1 \mathrm{~g}$ can be generated from $\beta$-fragmentation of radical $1 \mathrm{f}$ and the latter may be formed from $\mathbf{1 b}$ by $1,4-\mathrm{H}$ shift through a five-membered ring transition state. The carbon radical $\mathbf{1 h}$ on the peptide backbone may be obtained by a 1,2-H shift from radical intermediate $\mathbf{1 c}$ and $\beta$-fragmentation of $\mathbf{1 h}$ would cleave the side chain to form $\mathbf{1 k}$. Radical $\mathbf{1 b}$ may also give rise to $\mathbf{1 i}$ by loss of $\mathrm{NH}_{2}$ or $\mathbf{1 j}$ by $\beta$ fragmentation. The pathways that lead to other fragments, including 11 (m/z 281), $1 \mathbf{m}(\mathrm{m} / \mathrm{z} 253)$, and $1 \mathbf{n}(\mathrm{m} / \mathrm{z}$ 225) from peroxides in CID, have also been observed $[13,14]$. These proposed fragmentation pathways are consistent with the results obtained from study of two deuterated lysine analogues (Table 1). Consider, for example, formation of the a-ion $\mathbf{1 d}(\mathrm{m} / \mathrm{z} 149)$. The same fragment $m / z 149$ is observed when the $t$-butyl group on the peroxide is deuterated (parent ion $\mathrm{m} / \mathrm{z} 334$ ). However, a fragment with $\mathrm{m} / \mathrm{z} 152$ is generated when the methyl group of the acetyl is deuterated. It is of note that the free radical-induced pathways are observed in this model system only in CID spectra with adduct cations, such as $\mathrm{Li}^{+}, \mathrm{Na}^{+}, \mathrm{K}^{+}$, and $\mathrm{Ag}^{+}$, whereas the protonated ion generates totally different fragments. It seems likely that metal ions are needed for ionization because the modified lysine analogues lack a protonation site.

\section{CID Experiments of Modified Peptides at Lysine Sites Using ESI-MS}

We next studied a 7-mer peptide (N-Ac-GSAKVSF, $m / z$ 737.3) with one lysine residue and an acetylated $\mathrm{N}$ terminus. The CID of the protonated species of the unmodified peptide shows a series of b-ions (Figure 2a) that are consistent with the sequence of this peptide. After lysine modification, the CID spectrum of the protonated peptide $(\mathrm{m} / \mathrm{z}$ 853.2) is dominated by the $\mathrm{b}$-ions with the modification of $t$-butyl carbamate (ions with asterisks) attached to lysine. The minor fragments generated from the unmodified peptide $(\mathrm{m} / \mathrm{z} 737.3) \mathrm{can}$ also be observed. The mechanisms for the formation of the unmodified peptide in the CID spectrum are unknown but it has been proposed to be derived from the 


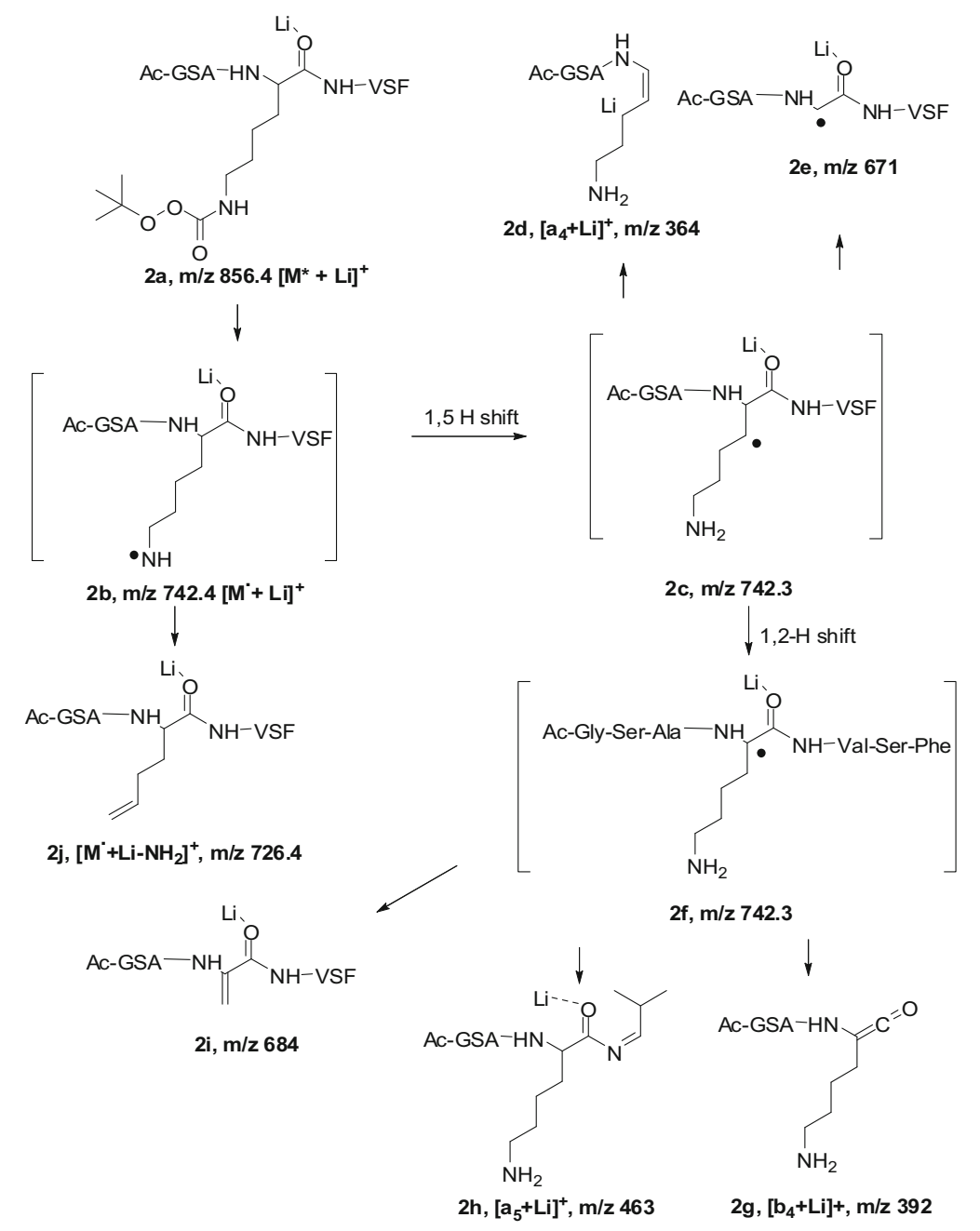

Scheme 3

hydrogen atom abstract of the intermediate aminyl radical. It is of interest, however, that the lithium adduct of the modified peptide $(\mathrm{m} / \mathrm{z}$ 859.6) generates a completely different sets of ions in the CID spectrum. Formation of these novel ions can be understood by the free-radical pathways initiated by the homolytic cleavage of the peroxide bond followed by decarboxylation (Scheme 3).

The a-type fragment $2 \mathbf{d}\left(\left[\mathrm{a}_{4}+\mathrm{Li}\right]^{+}, m / z 364\right)$ may be formed from the radical intermediate $2 \mathrm{c}$ that is a $1,5-\mathrm{H}$ shift product of the initial aminyl radical $2 \mathbf{b}$. A b-type ketene fragment $\mathbf{2} \mathbf{g}\left(\left[\mathrm{b}_{4}+\mathrm{Li}\right]^{+}, m / z\right.$ 392) can be derived from the $\beta$-fragmentation of radical $2 \mathbf{f}$ that is the $1,2-\mathrm{H}$ shift product of $2 \mathrm{c}$. These two types of peptide cleavage products can be used to aid peptide sequencing. The other side-chain cleavage fragments are also observed from the free radical-induced decomposition of the lithium adduct of the lysine modified peptide $2 \mathbf{a}$. It is of note that the fragment $2 \mathrm{~h}\left(\left[\mathrm{a}_{5}+\mathrm{Li}\right]^{+}, m / z 463\right)$ may be derived from a radical that migrates along the peptide backbone from the radical on the $\alpha$-carbon of the lysine side chain [16]. Fragments $\mathbf{2 e}, \mathbf{2} \mathbf{i}$, and $\mathbf{2} \mathbf{j}$ have also been observed in the decomposition of $\mathrm{Li}$ adduct of $\mathbf{1 a}$
(Scheme 2). Overall, the different CID spectra of protonated and lithium adduct of this modified 7-mer peptide is intriguing and it may be attributable to the hydrophobicity of this peptide. Lysine is the only polar amino acid in this peptide. After the modification, metal ion complexation is needed to observe products of the free-radical pathways.

To test whether the metal ion cationization is required for the observed free-radical pathways of peptide decomposition, we next investigate an 11-mer peptide with more polar amino acids in the sequence, YEHHQKLVFF $(\mathrm{m} / \mathrm{z}$ 1445.75). This peptide is readily modified by our method and generates triply and doubly charged species. The total ion chromatogram (TIC) of singly modified peptide shows two peaks with $m / z$ 782.20. It is evident that, besides the lysine modification, the N-terminus can be modified under our experimental conditions (see below). As expected, series of $b$ - and $y$-ions dominate the spectrum of the unmodified peptide $\mathrm{m} / \mathrm{z} 724.3$ (Figure 2b). In the case of the modification on lysine, it is interesting to see that the modification preferentially induces fragmentation near the lysine site. Series of fragments $b_{6}, c_{6}, a_{6}^{2+}$ 
(a)

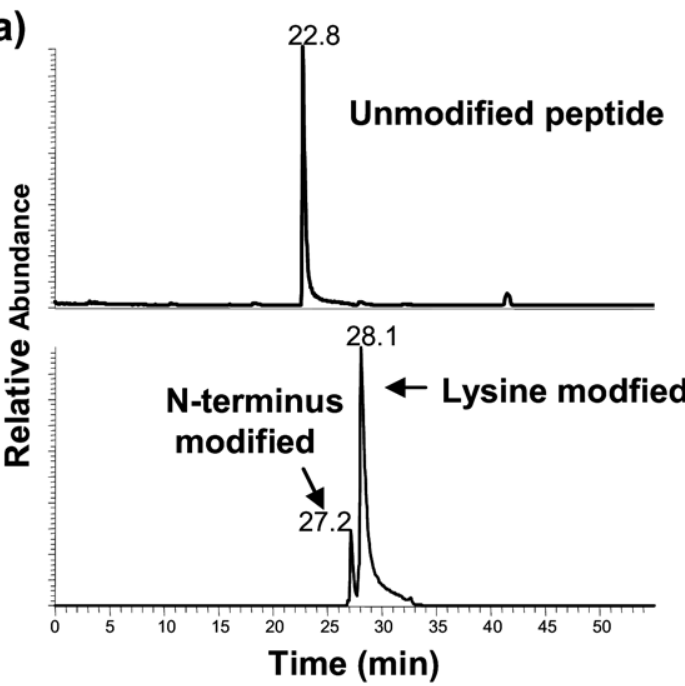

(c)

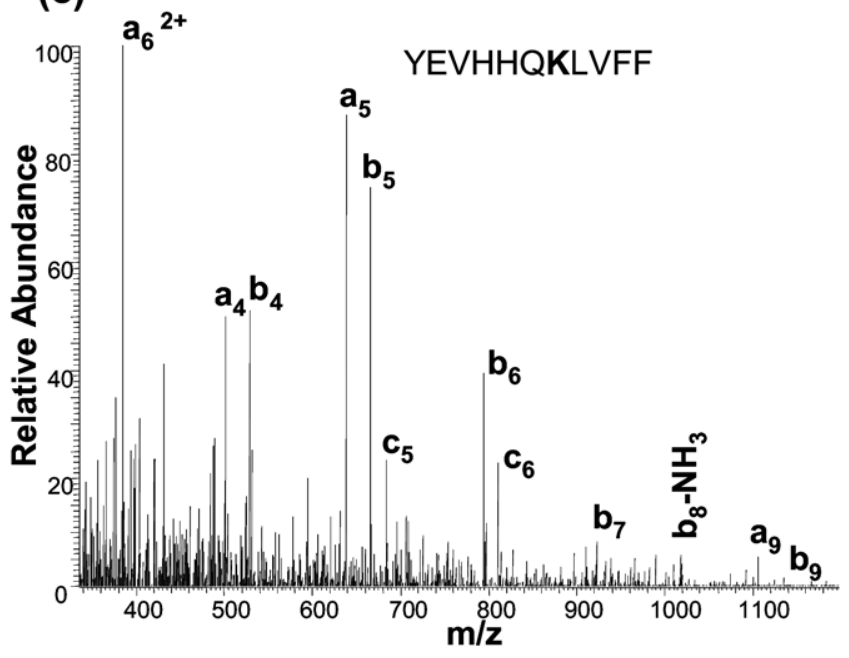

(b)

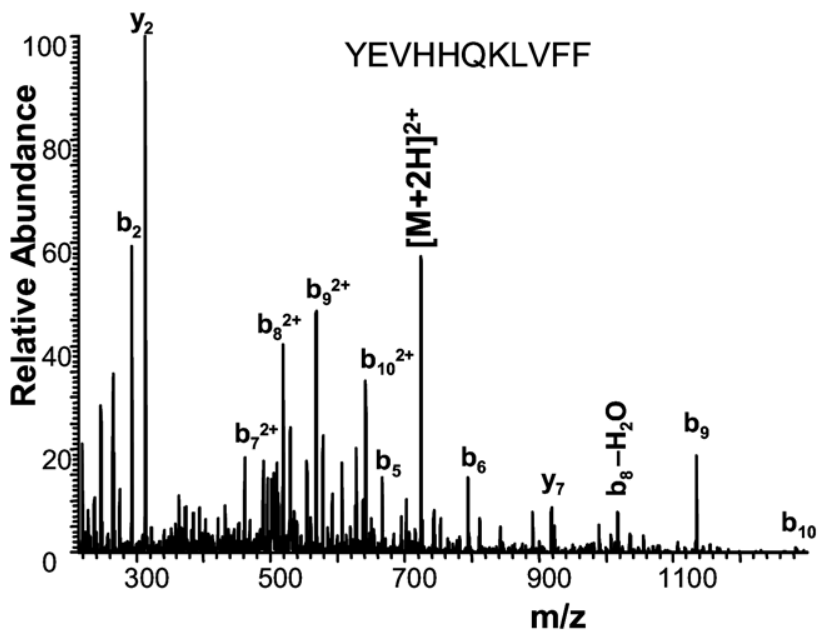

(d)

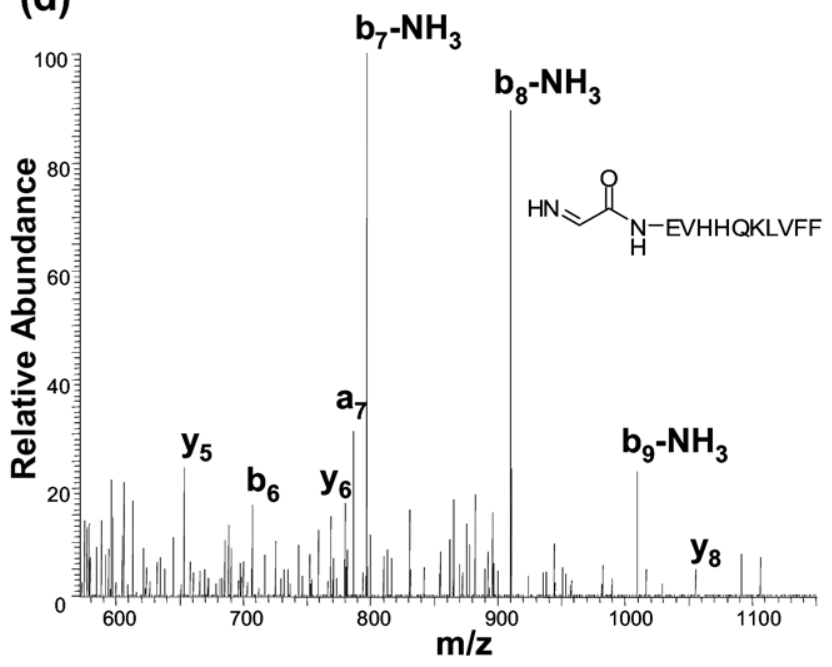

Figure 3. CID of unmodified and modified peptide YEVHHQKLVFF. (a) TIC of unmodified and Nand lysine-modified peptide. (b) CID of unmodified peptide $[\mathrm{M}+2 \mathrm{H}]^{2+} \mathrm{m} / \mathrm{z} 723.98$ (retention time at $22.7 \mathrm{~min}$ ); (c) CID of lysine-modified peptide $\mathrm{m} / \mathrm{z} 782.20$ (retention time at $28.0 \mathrm{~min}$ ); (d) CID of $\mathrm{N}$-terminus-modified peptide $\mathrm{m} / \mathrm{z} 782.20$ (retention time at $27.2 \mathrm{~min}$ ).

are observed in the CID spectrum after lysine modification (Figure 3c). On the other hand, modification of the N-terminus by this peroxycarbonate method induces the same type of radical fragmentation, which can be used to identify the amino acid at the $\mathrm{N}$-terminus [11]. Generally an imine fragment will be generated in this modification and the neutral loss of the side chain is amino acid dependent. The observation of lysinespecific fragments is important because the lysine modification by peroxycarbonate may aid the peptide sequencing. It seems that metal ion is not necessary in peptides with multiple protonation sites.

\section{Modified Peptides Studied by MALDI MS}

The selectively modified peptides by peroxycarbonate were also studied using MALDI MS. The same types of fragmentation are induced by the apparent free-radical pathways as observed in the CID of ESI-MS. The results of a model peptide with $\mathrm{N}$-Ac-SYSMEHFRWGKPVGKKR are illustrated in Figure 4.

The free radical-induced fragments $\mathrm{a}_{11}, \mathrm{a}_{15}$, and $\mathrm{a}_{16}$ are observed only in the modified peptide (Figure $4 \mathrm{~b}$ ) but not in the native peptide (Figure 4a). Further MS/MS experiments are carried out to sequence the fragments of $\mathrm{a}_{11}, \mathrm{a}_{15}$, and $\mathrm{a}_{16}$, and the results of $\mathrm{a}_{11}$ are shown in Figure 4c. Moderate sequence coverage is obtained in these experiments. The MALDI experiments demonstrated the feasibility of this selective modification of lysine by peroxycarbonate to aid peptide sequencing.

We tested more peptides using the MALDI MS and the results are summarized in Table 2 . Predominant a- 


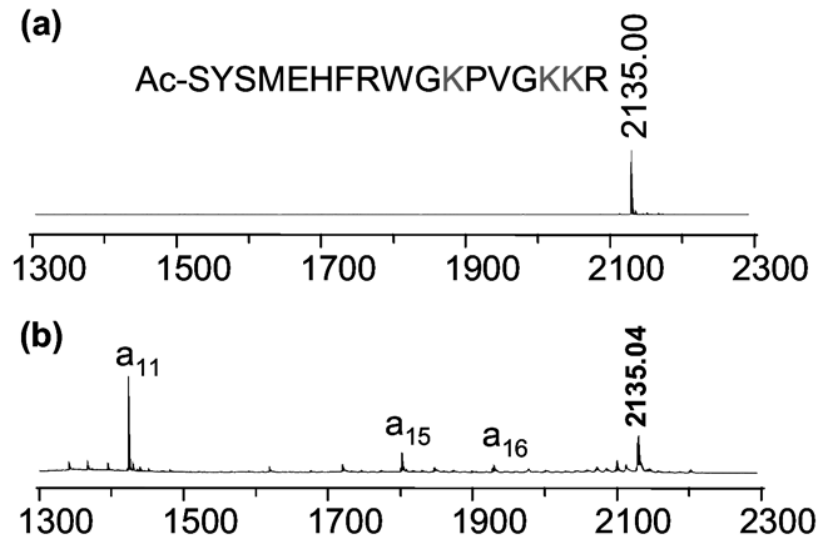

(c)

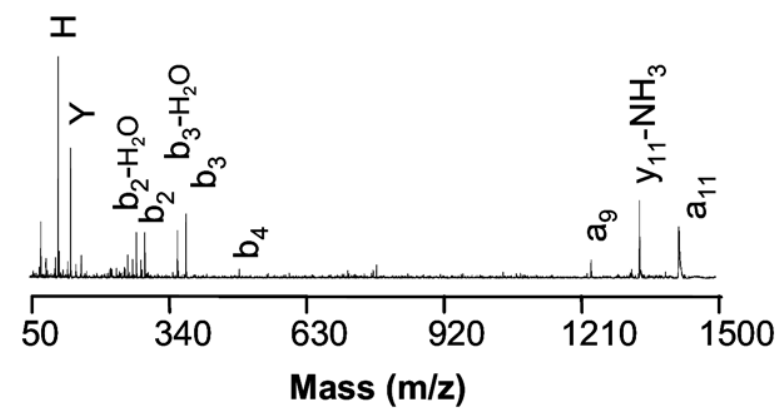

Figure 4. MALDI MS spectra of a 17-mer peptide. (a) Unmodified peptide; (b) modified peptide; (c) MS/MS spectrum of $\mathrm{a}_{11}$ derived from the selective modification of lysine at position 11.

or z-ions are observed at the lysine site with one lysine or multiple lysines in the sequence. The cleavage of the peptide induced by the free-radical pathways is mild, as can be seen in entry 4 under the MALDI condition, because the disulfide bond in this peptide is intact whereas the peptide bond near the modified lysine is cleaved. Under the same modification conditions, the $\mathrm{N}$-terminus can also be modified to some extent and the similar free-radical processes give rise to the loss of side chain of the amino acid at the N-terminus. The free-radical chemistry was recently explored to determine the N-terminus of peptides or proteins [11]. For example, in entry 1 , the loss of side chain of valine at the $\mathrm{N}$-terminus results in a fragment with $\mathrm{m} / \mathrm{z}$ 961.45, whereas in entries 2, 3, and 5 side-chain loss of lysine, tyrosine, and serine are observed, respectively, in MALDI spectra.

\section{Discussion}

The radical processes in the gas phase of MS have been extensively studied. The radical species can be generated by metal ion complexation [17], incorporation of an initiator moiety in the peptides [18], or ECD [16]. These studies provide insights into the gas-phase chemistry of peptides. Modification of lysine in a peptide by peroxycarbonate can induce site-specific peptide cleavage in the gas phase of low-energy CID or MALDI
(Scheme 4a). The fragments appear to be derived from the free radical-induced pathways by the homolytic cleavage of the peroxyl bond followed by decarboxylation. The initial aminyl radical undergoes hydrogen atom abstraction to form carbon-centered radicals either on the side chain of lysine or $\alpha$-carbon of lysine on the backbone. Further $\beta$-fragmentation can occur to give rise to the observed peptide cleavage fragments or side-chain loss.

There are several competitive pathways for the aminyl radical: $1,4-\mathrm{H}$ and $1,5-\mathrm{H}$ shifts give rise to intermediate radicals through a five- or six-membered ring transition state. The carbon-centered radical on the $\alpha$-carbon of lysine can be formed from a $1,5-\mathrm{H}$ shift followed by a 1,2- $\mathrm{H}$ shift. Furthermore, this carbon radical can migrate to the next amino acid before the $\beta$-fragmentation occurs. The formation of a fragment $2 \mathrm{~h}$ from the modified 7-mer 2a seems consistent with the migration of this radical [16]. In the low-energy CID process, a-, b-, c-, and z-series of ions can be generated from the parent aminyl radical. Some of these fragments can be used for sequencing.

The free-radical pathways in the low-energy CID process reported here are reminiscent of the mechanisms proposed for the peptide cleavage and side-chain loss observed in low-energy ECD (Scheme $4 \mathrm{~b}$ ). It is well accepted that the ECD is initiated from electron capturing by a multiply charged peptide species in the gas phase followed by a hydrogen atom transfer to form a carbon radical on the backbone that can cleave the peptide bonds or side chains [4, 19-22]. The low-energy ECD process preferentially cleaves backbone peptide over side-chain loss, allowing the identification of labile side-chain modification. This technique has been widely used in the top-down approach of proteomics $[12,23]$. In ECD, c- and z-ions are predominant over the $\mathrm{b}$ - and y-ions. The initial radical species can be generated from several amino acids that can be positively charged, such as histidine. Our strategy selectively derivatizes lysine residue or $\mathrm{N}$-terminus in a peptide or protein, which may aid the protein sequencing in proteomic studies and offer an alternative to enzymatic digestions.

In summary, lysine and $\mathrm{N}$-terminus in peptides can be selectively modified by $t$-butyl peroxycarbonate and the resulting peroxycarbamate undergoes site-specific cleavage in the gas phase of CID using ESI-MS or MALDI MS. The rich fragmentation pathways are consistent with the initial homolytic cleavage of the peroxyl bond followed by decarboxylation. Some of the fragments can be used for peptide sequencing in proteomics studies. We have carried out studies on some model proteins and our preliminary results showed that multiple lysines in the proteins can be modified by our strategy. However, the fragmentation is complex and research continues to be carried out to study the chemistry at the protein level. 


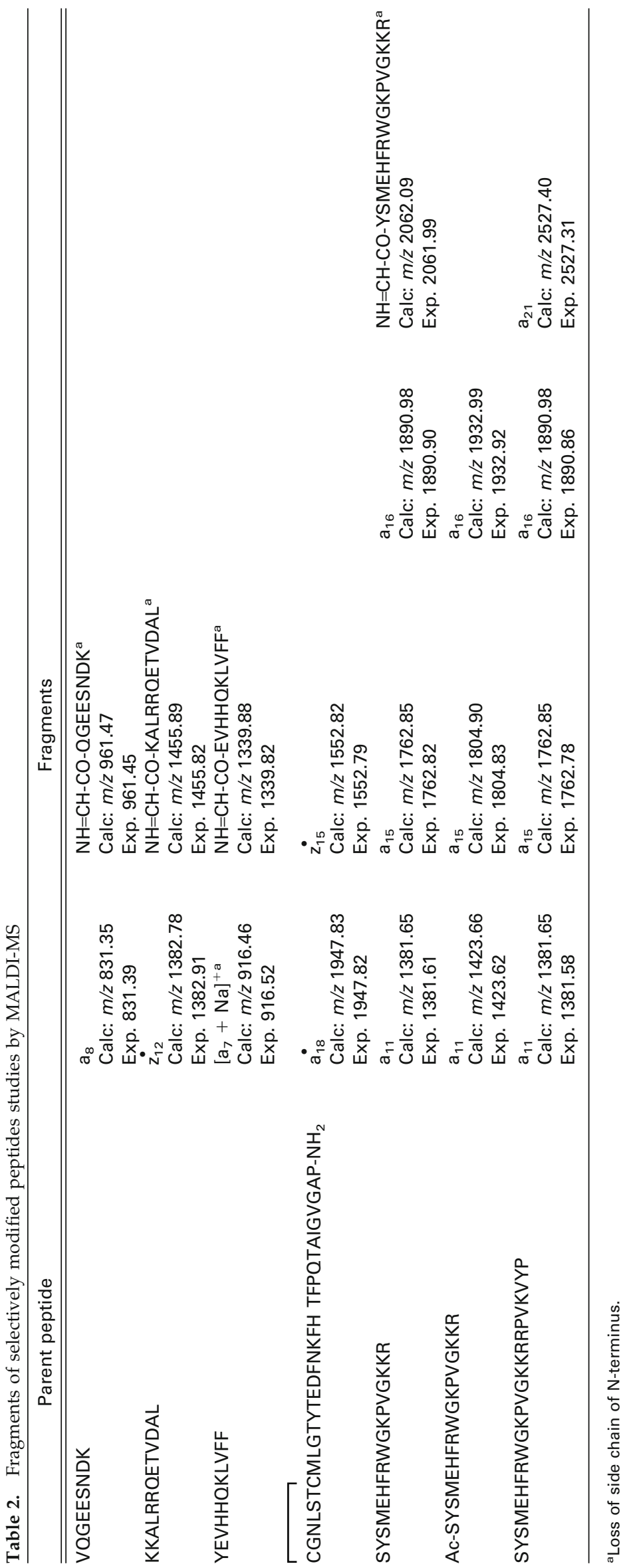


(a) side chain loss
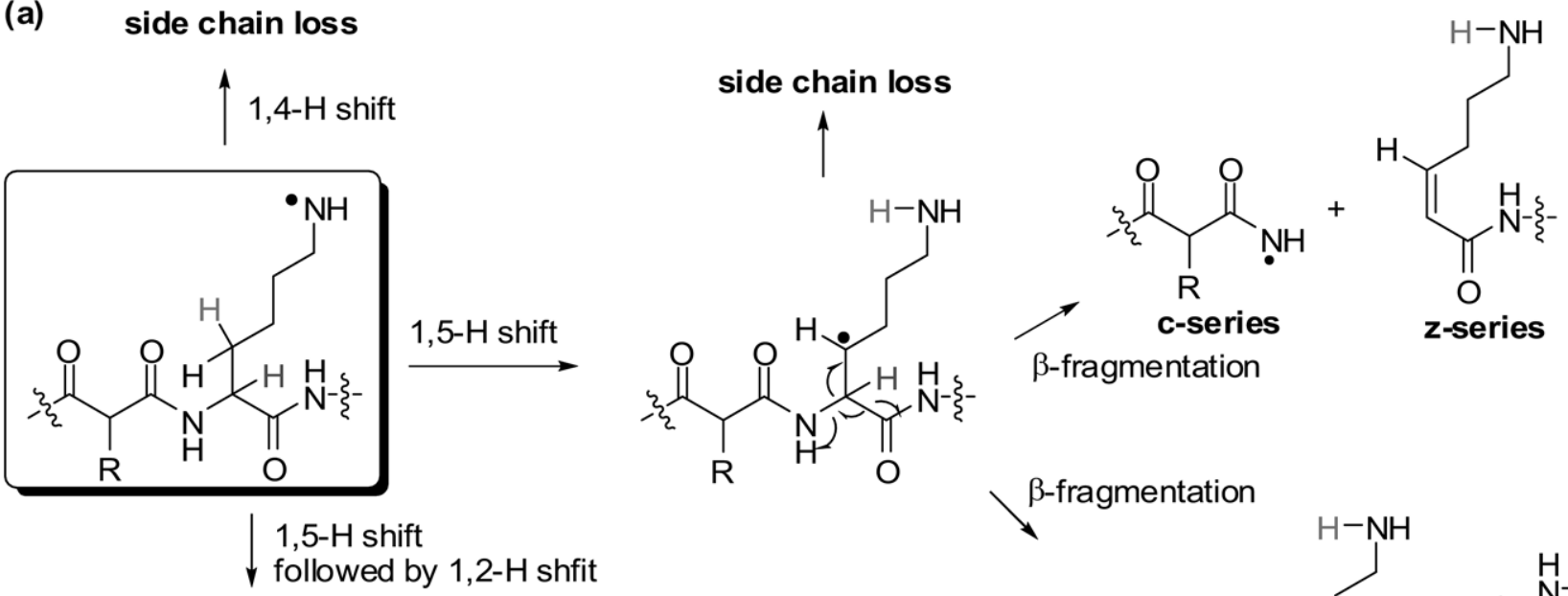

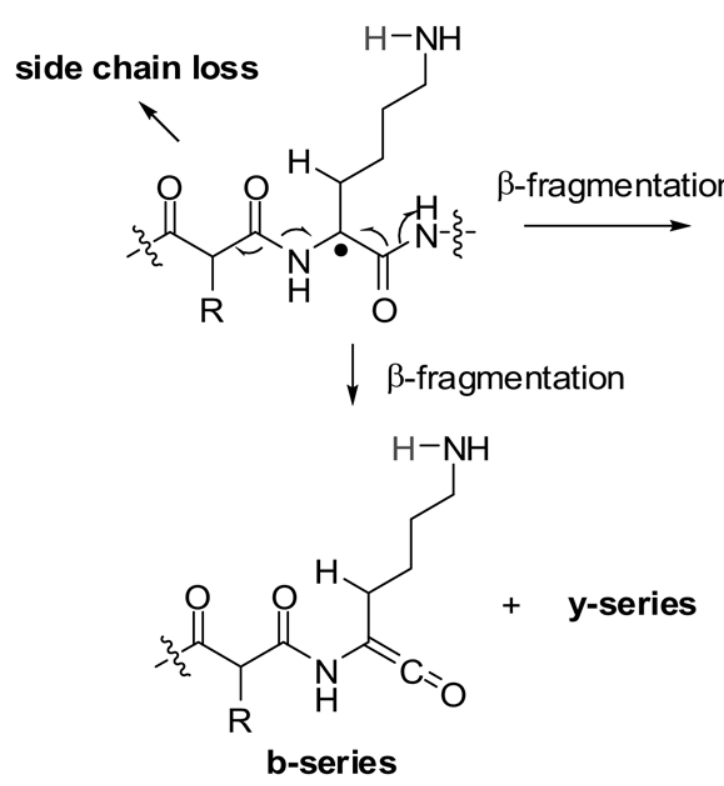

(b)

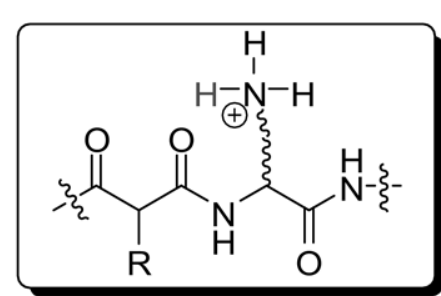

ECD $\downarrow e^{-}$

b-series<smiles>[R]C(C(C)=O)C(C)=O</smiles>

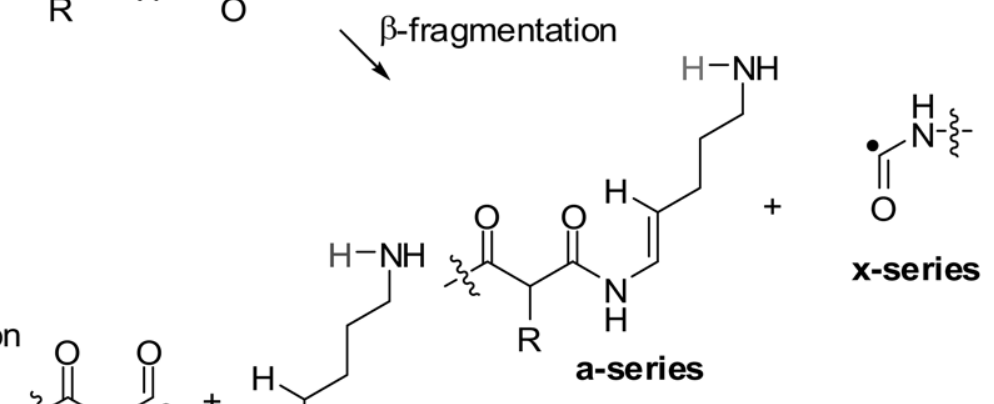

$\beta$-fragmentation

z-series

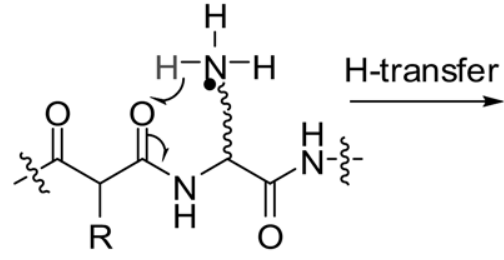

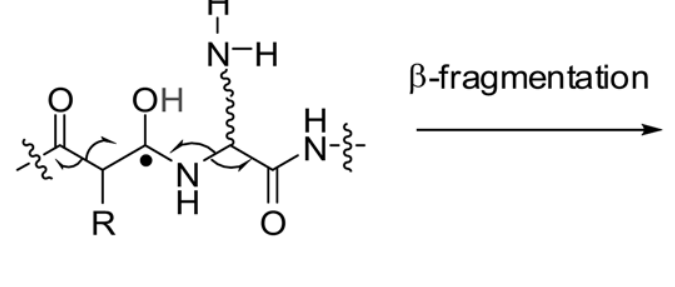<smiles>CCC(C)C(N)=O</smiles>

z-series

$+$<smiles>[R]C(C(=N)O)C(=O)O</smiles>

Scheme 4 


\section{Acknowledgments}

The authors gratefully acknowledge the financial support from the National Science Foundation (Grant NSF CHE 0107697), the Vanderbilt Center for Research in Toxicology, and Vanderbilt University. We thank Dr. Jeremy Norris and Dr. Richard Caprioli at Vanderbilt University for their help with MALDI experiments. We also thank the staff at Vanderbilt's Mass Spectrometry Research Center, in particular Dr. David Hachey, Lisa Manier, and Dawn Overstreet, for advice in use of MS instrumentation.

\section{References}

1. Aebersold, R.; Goodlett, D. R. Mass Spectrometry in Proteomics. Chem. Rev. 2001, 101, 269-296.

2. Bogdanov, B.; Smith, R. D. Proteomics by FTICR Mass Spectrometry: Top Down and Bottom Up. Mass Spectrom. Rev. 2005, 24, 168-200.

3. Domon, B.; Aebersold, R. Mass Spectrometry and Protein Analysis. Science 2006, 312, 212-217.

4. Cooper, H. J.; Hakansson, K.; Marshall, A. G. The Role of Electron Capture Dissociation in Biomolecular Analysis. Mass Spectrom. Rev. 2005, 24, 201-222.

5. Beardsley, R. L.; Karty, J. A.; Reilly, J. P. Enhancing the Intensities of Lysine-terminated Tryptic Peptide Ions in Matrix-assisted Laser Desorption/Ionization Mass Spectrometry. Rapid Commun. Mass Spectrom. 2000, 14, 2147-2153.

6. Gygi, S. P.; Rist, B.; Gerber, S. A.; Turecek, F.; Gelb, M. H.; Aebersold, R. Quantitative Analysis of Complex Protein Mixtures Using Isotopecoded Affinity Tags. Nat. Biotechnol. 1999, 17, 994-999.

7. Kelleher, N. L.; Lin, H. Y.; Valaskovic, G. A.; Aaserud, D. J.; Fridriksson, E. K.; McLafferty, F. W. Top Down versus Bottom Up Protein Characterization by Tandem High-Resolution Mass Spectrometry. J. Am. Chem. Soc. 1999, 121, 806-812.

8. Sze, S. K.; Ge, Y.; Oh, H.; McLafferty, F. W. Top-down Mass Spectrometry of a 29-kDa Protein for Characterization of Any Posttranslational Modification to within One Residue. Proc. Natl. Acad. Sci. U.S.A. 2002, 99, 1774-1779.

9. Roepstorff, P.; Fohlman, J. Proposal for a Common Nomenclature for Sequence Ions in Mass Spectra of Peptides. Biol. Mass Spectrom. 1984, 11, 601.
10. Masterson, D. S.; Yin, H.; Chacon, A.; Hachey, D. L.; Norris, J. L.; Porter N. A. Lysine Peroxycarbamates: Free Radical-promoted Peptide Cleavage. J. Am. Chem. Soc. 2004, 126, 720-721.

11. Chacon, A.; Masterson, D. S.; Yin, H.; Liebler, D. C.; Porter, N. A N-Terminal Amino Acid Side-chain Cleavage of Chemically Modified Peptides in the Gas Phase: A Mass Spectrometry Technique for Nterminus Identification. Bioorg. Med. Chem. 2006, 14, 6213-6222.

12. Reid, G. E.; McLuckey, S. A. Top Down Protein Characterization via Tandem Mass Spectrometry. J. Mass Spectrom. 2002, 37, 663-675.

13. Yin, H.; Hachey, D. L.; Porter, N. A. Structural Analysis of Diacyl Peroxides by Electrospray Tandem Mass Spectrometry with Ammonium Acetate: Bond Homolysis of Peroxide-Ammonium and PeroxideProton Adducts. Rapid Commun. Mass Spectrom. 2000, 14, 1248-1254.

14. Yin, H.; Hachey, D. L.; Porter, N. A. Analysis of Diacyl Peroxides by $\mathrm{Ag}^{+}$Coordination Ionspray Tandem Mass Spectrometry: Free Radical Pathways of Complex Decomposition. J. Am. Soc. Mass Spectrom. 2001, 12, 449-455.

15. Majetich, G.; Wheless, K. Remote Intramolecular Free Radical Functionalizations: An Update. Tetrahedron 1995, 51, 7095-7129.

16. O'Connor, P. B.; Lin, C.; Cournoyer, J. J.; Pittman, J. L.; Belyayev, M.; Budnik, B. A. Long-lived Electron Capture Dissociation Product Ions Experience Radical Migration via Hydrogen Abstraction. J. Am. Soc. Mass Spectrom. 2006, 17, 576-585.

17. Chu, I. K.; Rodriquez, C. F.; Lau, T.-C.; Hopkinson, A. C.; Siu, K. W. M. Molecular Radical Cations of Oligopeptides. J. Phys. Chem. B 2000, 104, 3393-3397.

18. Hodyss, R.; Cox, H. A.; Beauchamp, J. L. Bioconjugates for Tunable Peptide Fragmentation: Free Radical Initiated Peptide Sequencing (FRIPS). J. Am. Chem. Soc. 2005, 127, 12436-12437.

19. Leymarie, N.; Costello, C. E.; O'Connor, P. B. Electron Capture Dissociation Initiates a Free Radical Reaction Cascade. J. Am. Chem. Soc. 2003 $125,8949-8958$.

20. Syrstad, E. A.; Stephens, D. D.; Turecek, F. Hydrogen Atom Adducts to the Amide Bond. Generation and Energetics of Amide Radicals in the Gas Phase. J. Phys. Chem. A 2003, 107, 115-126.

21. Zubarev, R. A. Reactions of Polypeptide Ions with Electrons in the Gas Phase. Mass Spectrom. Rev. 2003, 22, 57-77.

22. Turecek, F.; Syrstad, E. A. Mechanism and Energetics of Intramolecular Hydrogen Transfer in Amide and Peptide Radicals and CationRadicals. J. Am. Chem. Soc. 2003, 125, 3353-3369.

23. Horn, D. M.; Zubarev, R. A.; McLafferty, F. W. Automated De Novo Sequencing of Proteins by Tandem High-resolution Mass Spectrometry. Proc. Natl. Acad. Sci. U.S.A. 2000, 97, 10313-10317. 